Saavedra: None declared, J. Fonseca Consultant for: AbbVie, Ache, Amgen, Biogen, BMS, Janssen, Lilly, MSD, Novartis, Pfizer, Roche, UCB, K. Lundin Grant/ research support from: MSD, Consultant for: Takeda, Orion, AbbVie, Rfizer, MSD, D. Warren: None declared, E. Haavardsholm Consultant for: AbbVie, Pfizer, MSD, Roche, UCB, J. Jahnsen Consultant for: AbbVie, Takeda, Janssen, Celltrion, Napp, AstroPharma, Hikma, Orion, Pfizer, T. Kvien Consultant for: AbbVie, Biogen, Eli Lilly, Novartis, Pfizer, MSD, Roche, UCB, Boehringer Ingelheim, Orion Pharma, J. Goncalves Consultant for: AbbVie, Amgen, Biogen, MSD, Pfizer DOI: 10.1136/annrheumdis-2018-eular.5554

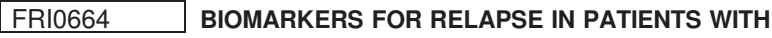 ADULT ONSET STILL'S DISEASE TREATED WITH IL-6 INHIBITOR.}

H. Yamada ${ }^{1}$, Y. Kaneko ${ }^{1}$, T. Takeuchi ${ }^{1} .{ }^{1}$ Division of Rheumatology, Department of Internal Medicine, Keio University, Shinjuku, Tokyo, Japan

Background: Symptoms and laboratory data in patients with adult onset Still's disease patients (AOSD) at relapse are often non-specific. Especially in AOSD patients treated with tocilizumab, IL-6 receptor inhibitor, inflammatory markers such as C-reactive protein (CRP) and erythrocyte sedimentation rate (ESR) are almost normal despite flared disease activity.

Objectives: To identify useful biomarkers for assessing disease activity and relapse in AOSD patients treated with tocilizumab.

Methods: Consecutive AOSD patients diagnosed by Yamaguchi's criteria in our institution from January 2007 until January 2018 were reviewed. Clinical information was collected from their medical charts. Relapse was defined as a case who required immunosuppressive treatment intensification for AOSD according to their attending physicians. Biomarkers were compared between before relapse and at relapse.

Results: Forty eight patients with AOSD were enrolled. Thirty relapses during the observation period of 3.5 years were identified. At relapse, white blood cell count (WBC), CRP, ESR, serum ferritin levels, and serum lactate dehydrogenase (LDH) levels significantly increased compared to before relapse (WBC, 12123 $\pm 1238 / \mu \mathrm{L}$ vs $7184 \pm 607 / \mu \mathrm{L}, \mathrm{P}=0.002 ; \mathrm{CRP}, 4.37 \pm 1.08 \mathrm{mg} / \mathrm{dL}$ vs $0.32 \pm 0.18 \mathrm{mg} /$ $\mathrm{dL}, \mathrm{P}=0.003$; ESR $39.1 \pm 7.78 \mathrm{~mm} / \mathrm{hr}$ vs $6.67 \pm 1.46 \mathrm{~mm} / \mathrm{hr}, \mathrm{P}=0.001$; ferritin, 78.9 $\pm 30.9 \mathrm{ng} / \mathrm{mL}$ vs $24.9 \pm 3.8 \mathrm{ng} / \mathrm{mL}, \mathrm{P}=0.036 ; \mathrm{LDH}, 374.8 \pm 48.1 \mathrm{IU} / \mathrm{mL}$ vs $214.7 \pm 16.8$ $\mathrm{IU} / \mathrm{mL}, \mathrm{P}=0.005)$. Six patients were identified to experience relapse with fever, active synovitis, rush or lymphadenopathy while treated with tocilizumab. In patients treated with tocilizumab, while neither CRP nor ESR increased in all patients at relapse $(\mathrm{CRP}<0.30 \mathrm{mg} / \mathrm{dL}$ in all; ESR, $4.50 \pm 1.04 \mathrm{~mm} / \mathrm{hr}$ vs $3.75 \pm 1.18$ $\mathrm{mm} / \mathrm{hr}, \mathrm{P}=0.893)$, LDH was significantly elevated at relapse compared to before relapse $(451.2 \pm 92.1 \mathrm{IU} / \mathrm{mL}$ vs $211.2 \pm 24.6 \mathrm{IU} / \mathrm{mL}, P=0.04)$. WBC and serum ferritin levels tended to increase but with no significant difference (WBC: $14620 \pm 1547$ $/ \mu \mathrm{L}$ vs $9500 \pm 2285 / \mu \mathrm{L}, \mathrm{P}=0.21$; ferritin, $236.4 \pm 91.2 \mathrm{ng} / \mathrm{mL}$ vs $49.2 \pm 24.2 \mathrm{ng} / \mathrm{mL}$, $\mathrm{P}=0.091$ ).

Conclusions: Instead of CRP and ESR, LDH level was a useful clinical biomarker for relapse of AOSD, especially in those treated with tocilizumab.

Disclosure of Interest: None declared

DOI: 10.1136/annrheumdis-2018-eular.3858

\section{FRI0665 IMPACT OF THE MULTI-BIOMARKER DISEASE ACTIVITY SCORE RESULTS ON WHETHER RHEUMATOLOGISTS CHANGED BIOLOGIC THERAPY FOR RA PATIENTS}

J. Curtis ${ }^{1}$, K. Ford ${ }^{2}$, L. Chen ${ }^{1}$, H. Yun ${ }^{1}$, F. Xie ${ }^{1} .{ }^{1}$ University of Alabama at Birmingham, Birmingham, ${ }^{2}$ Myriad Genetics, Inc., South San Francisco, United States

Background: The multi-biomarker disease activity (MBDA) score is a validated test used to assess disease activity for patients with rheumatoid arthritis (RA). How it is used in clinical practice in the U.S. is unclear.

Objectives: We evaluated the likelihood that rheumatologists would add or switch biologic therapies based on the MBDA test result.

Methods: Using previously published methods, we linked results of MBDA tests obtained as part of routine clinical care to 2012-2014 Medicare fee for service claims data for RA patients. We characterized patients as being on a biologic or targeted synthetic DMARD in the 90 days prior to the MBDA test and evaluated biologic/to facitinib treatment changes in the 90 days following the MBDA test. MBDA test scores were classified as low $(<30)$, moderate $(30-44)$, and high $(>44)$. The unit of analysis was the 90-day interval before and after each MBDA test score. Alternating logistic regression was used to compute odds ratios (OR) to quantify the likelihood that patients made any change (add or switch), accounting for the clustered nature of the data (intervals nested within patients, and patients nested within doctor practices) and physician-level variability, controlling for patient age and sex. Sensitivity analyses used a 6-month interval for outcome ascertainment after the MBDA test.

Results: Using previously validated methods, a total of 27,621 unique RA patients were linked to 44,438 MBDA test scores. For the 27,256 intervals where RA patients were not on biologic therapy when the MBDA score was obtained, a total of $13.2 \%$ of patients added a biologic. Patients with high MBDA scores were significantly more likely to add a biologic (table 1). For the 17,182 intervals where RA patients were already on a biologic, a total of $19.1 \%$ of patients switched or stopped the biologic that they were taking. Patients with lower MBDA scores were significantly more likely to stay on their therapy, whereas those with higher scores were more likely to stop and/or switch biologics. After adjustment, results from the regression analyses showed that patients with moderate MBDA scores were 1.47 (95\% 1.29-1.67)-fold more likely to add or switch biologics, and those with high MBDA scores were 2.54 (95\% Cl 2.19-2.94)-fold more likely to add or switch biologics. Men $(\mathrm{OR}=0.90,95 \% 0.82-0.98)$ and older patients $(\mathrm{OR}=0.92$ per 5 year increment, $95 \% \mathrm{Cl} 0.91-0.93$ ) were less likely to add or switch therapy, even after controlling for variability between physicians (OR=1.10, 95\% Cl 1.02-1.19). These results were robust and ORs were numerically larger when extending the interval to 6 months.

Table 1 Proportion of patients who added or switching biologics after the MBDA test

\begin{tabular}{|c|c|c|}
\hline $\begin{array}{l}\text { MBDA } \\
\text { Score }\end{array}$ & $\begin{array}{l}\text { Non-biologic users who } \\
\text { added a biologic after the } \\
\text { MBDA test } \\
\mathrm{N}=27,256\end{array}$ & $\begin{array}{l}\text { Biologic Users Who Switched or Stopped } \\
\text { their Current Biologic after the MBDA } \\
\text { test } \\
\mathrm{N}=17,182\end{array}$ \\
\hline Low $(<30)$ & $8.4 \%$ & $14.0 \%$ \\
\hline $\begin{array}{l}\text { Moderate } \\
(30-44)\end{array}$ & $10.8 \%$ & $16.2 \%$ \\
\hline $\begin{array}{l}\text { High } \\
(>44)\end{array}$ & $16.3 \%$ & $23.1 \%$ \\
\hline $\begin{array}{l}\text { Chi- } \\
\text { square p } \\
\text { value }\end{array}$ & $<0.0001$ & $<0.0001$ \\
\hline
\end{tabular}

Conclusions: Results from the MBDA score were significantly associated with the likelihood that a physician added or switched biologic therapies, with either type of change being more frequent when the MBDA score was high. Further evaluation of outcomes after switching, conditional on the MBDA score, is warranted. Acknowledgements: Financial support provided by Crescendo Bioscience Inc. Disclosure of Interest: J. Curtis Grant/research support from: AbbVie, Amgen, BMS, Corrona, Janssen, Lilly, Myriad, Pfizer, Roche/Genentech, UCB, Consultant for: AbbVie, Amgen, BMS, Corrona, Janssen, Lilly, Myriad, Pfizer, Roche/ Genentech, UCB, K. Ford Employee of: Myriad Genetics, Inc., L. Chen: None declared, H. Yun Grant/research support from: BMS, F. Xie: None declared DOI: 10.1136/annrheumdis-2018-eular.5779

\section{FRI0666 CIRCULATING MIR-99B-5P AS A PREDICTOR OF EROSION PROGRESSION IN EARLY RHEUMATOID ARTHRITIS: A 1-YEAR FOLLOW-UP STUDY BY HR- PQCT}

J. Yue $^{1}$, J. F. Griffith ${ }^{2}$, J. Xu ${ }^{3}$, F. Xiao ${ }^{2}$, L. Shi ${ }^{2}$, D. Wang ${ }^{2}$, P. C. Wong ${ }^{1}$, E. K. Li ${ }^{1}$, M. Li ${ }^{1}$, T. K. Li ${ }^{1}$, T. Y. Zhu ${ }^{3}$, V. Hung ${ }^{3}$, L. Qin ${ }^{3}$, L.-S. Tam ${ }^{1}$. ${ }^{1}$ Department of Medicine \& Therapeutics, ${ }^{2}$ Department of Imaging and Interventional Radiology,

${ }^{3}$ Department of Orthopedics \& Traumatologygy, Prince of Wales Hospital, The Chinese University of Hongkong, Hongkong, Hong Kong

Background: Bone erosion is a key feature of RA reflecting both disease severity and progression. HR-pQCT is an in-vivo clinical imaging system allowing detailed analysis of bone structure, including bone erosion. Several circulating microRNAs have already been suggested as potential biomarkers in RA.

Objectives: To determine whether plasma cell-free circulating miRNAs are 1) associated with bone erosion at presentation and 2) predictive of erosion progression at 12 months as determined by HR-pQCT in patients with early rheumatoid arthritis (ERA).

Methods: In this prospective study, 124 ERA patients were treated with a tight control protocol aiming at remission by using conventional synthetic disease modifying anti-rheumatic drugs (csDMARDs). The second metacarpophalangeal joint (MCP2) was assessed for erosions by HR-pQCT at baseline and after 12 months. Plasma cell-free circulating miRNAs at baseline were identified by microRNA array in 10 treatment-naïve ERA patients with maximal erosion volume at MCP2 in 10 treatment-naïve ERA patients without erosion; and in 6 age- and sexmatched healthy controls. The 4 most dysregulated miRNAs were identified by TaqMan $^{\oplus}$ qRT-PCR in these same 20 ERA patients. Thereafter, the expression of these 4 selected miRNAs was validated in all 124 ERA patients at baseline.

Results: Of the 377 screened miRNAs, 155 miRNAs were detectable. 94 $(60.6 \%)$ of these detectable miRNAs were upregulated in ERA patient with erosions, with $13(8.4 \%)$ upregulated more than twofold. 61 (39.4\%) miRNAs were 